Boston University School of Law

Scholarly Commons at Boston University School of Law

Faculty Scholarship

1987

Protecting the Liberty of Pregnant Patients

George J. Annas

Follow this and additional works at: https://scholarship.law.bu.edu/faculty_scholarship

Part of the Health Law and Policy Commons 
5. Schatzkin A, Jones DY, Hoover RN, et al. Alcohol consumption and breast cancer in the Epidemiologic Follow-up Study of the First National Health and Nutrition Examination Survey. N Engl J Med 1987; 316:1169-73.

6. Marshall JR, Priore R. Graham S, Brasure J. On the distortion of risk estimates in multiple exposure level case-control studies. Am J Epidemiol $1981 ; 113: 464-73$.

7. Byers T, Funch DP. Alcohol and breast cancer. Lancet 1982; 1:799-801.

8. Paganini-Hill A, Ross RK. Breast cancer and alcohol consumption. Lancet $1983 ; 2: 626-7$.

9. Begg CB, Walker AM, Wessen B, Zelen M. Alcohol consumption and breast cancer. Lancet 1983; 1:293-4.

10. Webster LA, Layde PM. Wingo PA, Ory HW, Cancer and Steroid Hormone Study Group. Alcohol consumption and risk of breast cancer. Lancet 1983; 2:724-6.

\section{PROTECTING THE LIBERTY OF PREGNANT PATIENTS}

WE are seeing the beginning of an alliance between physicians and the state to force pregnant women to follow medical advice for the sake of their fetuses. ${ }^{1}$ No irreversible commitments to such an alliance have yet been made, but only a principled discussion of the issues is likely to prevent forced treatment from becoming standard medical practice.

In her futuristic novel The Handmaid's Tale, Margaret Atwood envisions a world in which physicians and the state combine to strip fertile women of all human rights. These women come to view themselves as "two-legged wombs, that's all; sacred vessels, ambulatory chalices." 2 To some that future is now. Typical "surrogate mother" contracts, like the one Mary Beth Whitehead signed, require the pregnant woman to follow all "medical instructions" and "not smoke cigarettes, drink alcoholic beverages, use illegal drugs, or take non-prescription medications or prescribed medications without written consent from her physician." When Ms. Whitehead refused to relinquish her child, another physician testified at trial that she was simply a "surrogate uterus." The judge himself declared the contract legally enforceable, in part because he viewed surrogacy as a mechanistic means to an end, a "viable vehicle" for infertile couples to "have a family." Some physicians also applauded the attempted criminal prosecution of a California woman for failure to follow her physician's advice during pregnancy. ${ }^{1,4}$ And in this issue of the Journal, Kolder et al. report that almost half the heads of fellowship programs in maternal-fetal medicine support involuntary detention of pregnant women whose behavior endangers their fetuses; more than a quarter advocate "state surveillance" during the third trimester to protect fetuses. ${ }^{5}$ Some obstetricians have already sought court orders to force various interventions on their pregnant patients. ${ }^{1,5}$

These attitudes and actions betray a profound suspicion of pregnant women and a failure to identify with them. Almost all the pregnant women involved in the reported physician-initiated court actions have been black, Asian, or Hispanic, and all were poor. ${ }^{5}$ Women from various ethnic backgrounds have profoundly differing religious and personal beliefs about discounted by physicians. ${ }^{6}$ Forcing pregnant women to follow medical advice also places unwarranted faith in that advice. Physicians often disagree about the appropriateness of obstetrical interventions, ${ }^{7}$ and they can be mistaken. In three of the first five cases in which court-ordered cesarean sections were sought, the women ultimately delivered vaginally and uneventfully. ${ }^{1}$ In the face of such uncertainty - uncertainty compounded by decades of changing and conflicting expert opinion on the management of pregnancy and childbirth - the moral and legal primacy of the competent, informed pregnant woman in decision making is overwhelming.

To be sure, disagreements between the doctor and the pregnant patient can be emotionally devastating to physicians because of their feelings of helplessness and vulnerability in the face of potential catastrophe, but disagreements are inevitable. The question is how they should be resolved. Traditionally, physicians have not been eager to involve judges actively in medical-treatment decisions, often arguing that this would interfere with the traditional doctor-patient relationship. Thus, there is irony in the promotion by even a few obstetricians - members of the specialty that sees itself as most besieged by malpractice litigation - of judicial intervention at the bedside. Is this a trend physicians should encourage?

Forcing compliance with medical advice implies that the fetus rather than the pregnant woman is the patient. The reality, however, is that the fetus can be treated without its mother's consent only by drastically curtailing her liberty during pregnancy or by subjecting her to major surgery at or near birth. The former could require the involuntary commitment of pregnant women who are addicted to alcohol or drugs; the latter argues for forced cesarean sections. One wonders how we would respond if we learned that a totalitarian regime was planning to force similar interventions on pregnant women for the sake of their fetuses.

Kolder et al. admirably and accurately note that the handful of court cases in the area of court-ordered obstetrical treatment "rest on dubious legal grounds." They could have gone further. In the vast majority of cases, judges were called on an emergency basis and ordered interventions within hours. The judge usually went to the hospital. Physicians should know what most lawyers and almost all judges know: When a judge arrives at the hospital in response to an emergency call, he or she is acting much more like a lay person than a jurist. Without time to analyze the issues, without representation for the pregnant woman, without briefing or thoughtful reflection on the situation, in almost total ignorance of the relevant law, and in an unfamiliar setting faced by a relatively calm physician and a woman who can easily be labeled "hysterical," the judge will almost always order whatever the doctor advises.

Physicians may feel better after being "blessed" by the judge, but they shouldn't. First, the appearance of legitimacy is deceptive; the judge has acted in- 
ful appeal. Second, the medical situation has not changed, except that more time has been lost that should have been used to continue discussion with the woman directly. And finally, the physician has now helped transform himself or herself into an agent of the state's authority.

It is not helpful to use the law to convert a woman's and society's moral responsibility to her fetus into the woman's legal responsibility alone. ${ }^{1,8}$ The best chance we have to protect fetuses is through enhancing the status of all women by fostering reasonable pay for the work they do, providing equal employment opportunities and adequate day care, providing a reasonable social safety net, and ensuring all pregnant women access to high-quality prenatal services. ${ }^{1}$ After birth, the fetus becomes a child and can thereafter be treated in its own right. Before birth, we can obtain access to the fetus only through its mother, and in the absence of her informed consent, can do so only by treating her as a fetal container, a nonperson without rights to bodily integrity.

Even from a strictly utilitarian perspective, this marriage of the state and medicine is likely to harm more fetuses than it helps, since many women will quite reasonably avoid physicians altogether during pregnancy if failure to follow medical advice can result in forced treatment, involuntary confinement, or criminal charges. By protecting the liberty of the pregnant patient and the integrity of a voluntary doctorpatient relationship, we not only promote autonomy; we also promote the well-being of the vast majority of fetuses.

Boston University Schools of Medicine and Public Health Boston, MA 02118

George J. Annas, J.D., M.P.H.

\section{References}

1. Elias S, Annas GJ. Reproductive genetics and the law. Chicago: Year Book, 1987.

2. Atwood M. The handmaid's tale. Boston: Houghton Mifflin, 1986.

3. Matter of baby "M." Superior Court of New Jersey, Chancery Division/ Family, Bergen County, FM-25314-86E, March 31, 1987 (Sorkow J).

4. Annas GJ. Pregnant women as fetal containers. Hastings Cent Rep 1986; $16(6): 13-4$.

5. Kolder VEB, Gallagher J, Parsons MT. Court-ordered obstetrical interventions. N Engl J Med 1987; 316:1192-6.

6. Hahn RA, Muecke MA. The anthropology of birth in five U.S. ethnic populations: implications for obstetrical practice. Curr Probl Obstet Gynecol Fertil 1987; 10:133-71

7. Notzon FC, Placek PJ, Taffel SM. Comparisons of national cesarean-section rates. N Engl J Med 1987; 316:386-9.

8. Engelhardt HT. The foundations of bioethics. New York: Oxford University Press, 1985:224-7.

\section{CORRESPONDENCE}

\section{STROKE AND ALCOHOL CONSUMPTION}

To the Editor: Gill et al. (Oct. 23 issue) ${ }^{1}$ claim to have demonstrated an association in men between heavy alcohol consumption and stroke. In their case-control study, the control group was made up of patients admitted to the hospital "for routine surgical procedures" after matching for age, sex, and race and after excluding "those who had conditions with a recognized association with exces- sive alcohol use (such as trauma, fractures, and peptic ulcer) or diseases known to alter liver function (including carcinoma and infections)." No such restrictions were imposed on the cases. This, in our view, may result in a control group preselected against high levels of alcohol consumption.

Although we are aware of the difficulties inherent in choosing hospital-based controls, it is generally accepted that controls should be representative of cases, if there were no association between disease and exposure. ${ }^{2}$ Could the restrictions imposed by Gill et al. on the controls but not on the cases have created a control group so unrepresentative of cases, if there were no association, that the study was biased in favor of a strong association?

Furthermore, although we realize that alcohol consumption is difficult to estimate when a retrospective approach is used, we question the authors' assertion that data collected years before the stroke may have little relevance to the short-term pathogenesis of the disease. It may be that the lifetime drinking history is a more useful and valid measure of the hazards of alcohol consumption than the average weekly estimate used.

Houston, TX 77030

Caterina Kiefe, Ph.D., M.D. Joer Freiman, M.D.

1. Gill JS, Zezulka AV, Shipley MJ, Gill SK, Beevers DG. Stroke and alcohol consumption. N Engl J Med 1986; 315:1041-6.

2. Schlesselman JJ. Case control studies: design. conduct, analysis. New York: Oxford University Press, 1982.

To the Edilor: The article by Dr. Gill and associates on stroke and alcohol consumption shows a definite association between heavy drinking and stroke. This may well be due to specific effects of the alcohol, but their paper did not show this. Unless they controlled for compliance with treatment for hypertension, it would be impossible to make the assumption that the alcohol alone was responsible for the increased risk of stroke. Heavy drinkers are notoriously poor compliers with medication regimens, and this is much more likely to be the cause of the association than alcohol itself.

I.Ourdes C. Corman, M.D. University of Florida

Gainesville, FL 32610 J. Hillis Miller Health Center

To the Editor: The results of the case-control study by Gill et al. provide new evidence of an independent effect of long-term heavy alcohol intake on the risk of stroke in men. We report here our experience in northeastern Italy, a wine-producing area where the level of alcohol consumption is one of the highest in the world and where alcohol abuse is still an important cause of morbidity and mortality.*

*De Marchi S, Cecchin E. Biological markers of alcohol intake among subjects injured in accidents. Br Med J 1986; 293:138.

Letters to the Editor are considered for publication (subject to editing and abridgment), provided that they are submitted in duplicate, signed by all authors, typewritten in double spacing, and do not exceed 40 typewritten lines of manuscript text (excluding references). Submission of a letter constitutes permission for the Massachusetts Medical Society, its licensees, and its assignees to use it in the Journal's various editions (print, data base, and optical disk) in anthologies, revisions, and any other form or medium. Letters should not duplicate similar material being submitted or published elsewhere, and they should not contain abbreviations. Financial associations or other possible conflicts of interest should always be disclosed.

Letters referring to a recent Journal article must be received within six weeks of the article's publication. We are unable to provide pre-publication proofs, and unpublished material will not be returned to authors unless a stamped, self-addressed envelope is enclosed. 